\title{
Adaptabilidade e estabilidade produtiva de genótipos de feijão-caupi de porte semi-ereto na Região Nordeste do Brasil
}

\author{
Maurisrael de Moura Rocha(1), Francisco Rodrigues Freire Filho(1), Valdenir Queiroz Ribeiro(1), \\ Hélio Wilson Lemos de Carvalho ${ }^{(2)}$, José Belarmino Filho(3), João Antônio Arruda Raposo(4), \\ José dos Prazeres Alcântara(5), Semíramis Rabelo Ramalho Ramos ${ }^{(2)}$ e Cristina de Fátima Machado ${ }^{(1)}$
}

\begin{abstract}
(1)Embrapa Meio-Norte, Caixa Postal 01, CEP 64006-220 Teresina, PI. E-mail: mmrocha@cpamn.embrapa.br, freire@cpamn.embrapa.br, valdenir@cpamn.embrapa.br, crisagronoma@yahoo.com.br (2)Embrapa Tabuleiros Costeiros, Caixa Postal 44, CEP $49025-040$ Aracaju, SE. E-mail: helio@cpatc.embrapa.br, srrramos@cpatc.embrapa.br (3)Empresa Estadual de Pesquisa Agropecuária da Paraíba, Caixa Postal 275, CEP 58013-290 João Pessoa, PB. (4)Empresa Pernambucana de Pesquisa Agropecuária, Av. General San Martin, no 1371, Bonji, CEP 50761-000 Recife, PE. E-mail: jraposo@ipa.br ${ }^{(5)}$ Empresa Baiana de Desenvolvimento Agrícola, Av. Dorival Caymmi, no 15.649, Itapuã, CEP 41635-150 Salvador, BA. E-mail: edbaitabe@sendnet.com.br
\end{abstract}

Resumo - O objetivo deste trabalho foi avaliar a adaptabilidade e a estabilidade da produtividade de grãos de 20 genótipos de feijão-caupi de porte semi-ereto, utilizando o modelo de efeitos aditivos principais e interação multiplicativa. Os ensaios foram conduzidos em 16 ambientes da Região Nordeste do Brasil. Os efeitos de genótipos, ambientes e da interação genótipo x ambiente, e os três primeiros eixos da análise de componentes principais (ACP) foram significativos. Os dois primeiros eixos da ACP explicaram juntos 55,11\% da soma de quadrados da interação, correspondendo a 83,20\% do padrão da interação genótipo x ambiente. As linhagens TE-97-321G-4, EVX-92-49E e EVX-63-10E apresentaram alta adaptabilidade, mas somente a última foi altamente previsível. A cultivar BRS Guariba e as linhagens EVX-92-49E e TE97-321G-4 expressam melhor potencial genético em ambientes de alta produtividade.

Termos para indexação: Vigna unguiculata, interação genótipo ambiente, efeitos principais aditivos e interação multiplicativa, AMMI.

\section{Yield adaptability and stability of semi-erect cowpea genotypes in the Brazil Northeast Region}

\begin{abstract}
The objective of this work was to evaluate the adaptability and the stability of the grain yield of 20 semierect cowpea genotypes, using the additive main effect and multiplicative interaction model. The trials were carried out in 16 environments of the Northeast Region of Brazil. The genotypes, environments and genotype $\mathrm{x}$ environment interaction, as well as the first three axes of the principal components analysis (PCA) were significant. The first two axes of the PCA explained $55.11 \%$ of the sum of squares of the genotype $x$ environment interaction, corresponding to $83.20 \%$ of the pattern of genotype $\mathrm{x}$ environment interaction. TE97-321G-4, EVX-92-49E and EVX-63-10E lines were highly adaptable, but only the last one was highly predictable. BRS Guariba cultivar as well as EVX-92-49E and TE97-321G-4 lines best express their genetic potential in environments of high yield.
\end{abstract}

Index terms: Vigna unguiculata, genotype environment interaction, additive main effect and multiplicative interaction model, AMMI.

\section{Introdução}

O feijão-caupi ou feijão-de-corda (Vigna unguiculata (L.) Walp.) é um componente da dieta alimentar de povos em países subdesenvolvidos. Sua importância está no alto conteúdo de proteína nas sementes (Akande, 2007). Os maiores produtores e consumidores mundiais são a Nigéria, Níger e Brasil (Singh et al., 2002).
Na Região Nordeste do Brasil, encontram-se as maiores áreas plantadas, e a cultura desempenha função de destaque sócioeconômico por ser a principal fonte de proteína vegetal, sobretudo para a população rural, além de fixar mão-de-obra no campo (Cardoso \& Ribeiro, 2006) e gerar emprego e renda na região (Freire Filho et al., 2005a). 
Nos últimos anos, a cultura vem despertando o interesse de agricultores que praticam agricultura empresarial, cuja lavoura é totalmente mecanizada. Isto tem levado a uma procura maior por cultivares com arquitetura de planta mais moderna, porte mais compacto e mais ereto (Freire Filho et al., 2006).

Na etapa de lançamento de cultivares de feijão-caupi, é fundamental o conhecimento da adaptabilidade e estabilidade dos genótipos, a fim de amenizar os efeitos da interação genótipo x ambiente e facilitar a recomendação de cultivares. Trabalhos têm sido desenvolvidos com esta cultura com o objetivo de estudar a adaptabilidade e a estabilidade de genótipos, com predominância de métodos que utilizam regressão linear (Eberhart \& Russel, 1966). Esses estudos têm subsidiado o melhoramento e o lançamento de cultivares de feijãocaupi em estados do Nordeste, no entanto, se concentram em genótipos de porte prostrado (Miranda et al., 1997; Santos et al., 2000; Freire Filho et al., 2002) e, em menor escala, em genótipos de porte ereto (Freire Filho et al., 2001).

Atualmente, têm-se buscado modelos alternativos de análises que expliquem melhor o comportamento de genótipos frente às variações ambientais. Assim, vem aumentando o uso do modelo de efeitos principais aditivos e interação multiplicativa AMMI ("Additive Main Effects and Multiplicative Interaction"), que combina a análise de variância, para os efeitos aditivos principais de genótipos e ambientes, com a análise de componentes principais para o efeito multiplicativo da interação genótipo x ambiente (Zobel et al., 1988; Duarte \& Vencovsky, 1999).

Trabalhos conduzidos em diferentes espécies, que comparam a análise AMMI e a regressão linear, mostraram que a primeira é mais eficiente em explicar a interação genótipo $\mathrm{x}$ ambiente. Dois estudos realizados em feijão-caupi no Brasil utilizaram o modelo AMMI para analisar a adaptabilidade e estabilidade de genótipos e ambientes e os resultados mostraram que a análise forneceu informações mais detalhadas quanto aos efeitos de genótipos, ambientes e da interação genótipo $\mathrm{x}$ ambiente (Freire Filho et al., 2003, 2005b). Em pesquisas conduzidas na África por Akande (2007), o modelo AMMI permitiu identificar e agrupar o padrão de adaptação de oito cultivares de feijão-caupi a dois ambientes.

Este trabalho teve como objetivo avaliar a adaptabilidade e a estabilidade da produtividade de grãos de 20 genótipos de feijão-caupi de porte semi-ereto, por meio do método AMMI.

\section{Material e Métodos}

Foram utilizados dados de produtividade de grãos de feijão-caupi de porte semi-ereto dos ensaios de valor de cultivo e uso do programa de melhoramento de feijãocaupi da Embrapa Meio-Norte, conduzidos nos anos agrícolas 2002 e 2003, nos estados do Maranhão, Piauí, Pernambuco, Sergipe, Bahia e Paraíba. Os tratamentos consistiram de 20 genótipos de porte semi-ereto: TE97-321G-4, TE97-404-1E-1, TE97-404-9E-1-1, TE97406-2E, TE97-406-2F-28-1, TE97-406-2F-28-2, TE97-4111F-9, TE97-411-1F-16, TE97-413-1E-10, TE97-413-1F-2, TE97-413-6F-2-5, TE97-367G-12-2, TE97-369G-4, BRS Guariba, EVX-47-6E, EVX-63-10E, EVX-91-2E-1, EVX-91-2E-2, EVX-92-49E e Vita-7.

Os ambientes de avaliação consistiram da combinação de local e ano, o que resultou em 16 ambientes: Brejo, MA, 2002 (BR02); Barra do Corda, MA, 2002 (BC02); São Raimundo das Mangabeiras, MA, 2002 (SR02); São Raimundo das Mangabeiras, MA, 2003 (SR03); Teresina, PI, 2002 (TE02); Baixa Grande do Ribeiro, PI, 2002 (BG02); Bom Jesus, PI, 2003 (BJ03); Serra Talhada, PE, 2002 (ST02); Serra Talhada, PE, 2003 (ST03); Nossa Senhora das Dores, SE, 2003 (NS03); Simão Dias, SE, 2003 (SD03); Umbaúba, SE, 2003 (UB03); Ribeira do Pombal, BA, 2002 (RB02); Itaberaba, BA, 2002 (IB02); Riacho dos Cavalos, PB, 2002 (RC02) e Itaporanga, PB, 2002 (IT02).

Todos os ensaios foram conduzidos sob regime de sequeiro, com plantio entre a última semana de fevereiro e a primeira semana de março. A colheita ocorreu sempre no final do período chuvoso. A adubação foi realizada de acordo com as recomendações para o solo de cada local, geralmente com a aplicação de 40 a $80 \mathrm{~kg} \mathrm{ha}^{-1}$ de $\mathrm{P}_{2} \mathrm{O}_{5}$ e de 20 a $40 \mathrm{~kg} \mathrm{ha}^{-1}$ de $\mathrm{K}_{2} \mathrm{O}$. Não foi realizada adubação nitrogenada, tendo em vista que o feijão-caupi é uma leguminosa que se beneficia da associação simbiótica com bactérias do gênero Rhizobium. Os tratos culturais consistiram do uso de herbicida (S-Metolachlor) e capina complementar para o controle de ervas daninhas, via pulverizador costal manual. Foi aplicado inseticida (Dimetoato e Thiamethoxam) para o controle de insetos mastigadores (vaquinhas e lagartas) e sugadores (pulgões, percevejos e trips), quando necessário, por pulverizador tratorizado de barras.

Em todos os ensaios, utilizou-se o delineamento experimental de blocos casualizados, com 20 tratamentos e quatro repetições. Cada parcela apresentou as dimensões 
de $2 \times 5 \mathrm{~m}$ e constou de quatro fileiras de $5 \mathrm{~m}$, tendo como área útil as duas fileiras centrais. $\mathrm{O}$ espaçamento entre fileiras foi de $0,50 \mathrm{~m}$, e dentro da fileira, o espaçamento foi de $0,20 \mathrm{~m}$ entre covas. Foram semeadas quatro sementes por cova e, 15 dias após a germinação, foi realizado o desbaste para uma planta por cova.

A adaptabilidade e a estabilidade de genótipos e ambientes foram analisadas pelo modelo de efeitos aditivos principais e interação multiplicativa (AMMI) (Zobel et al., 1988), o qual representa um modelo linear e bilinear, uni e multivariado, compreendendo análise integrada em que os efeitos aditivos principais de genótipos e ambientes foram investigados pela análise de variância, e o efeito multiplicativo da interação genótipo $\mathrm{x}$ ambiente (GA) foi decomposto pela análise de componentes principais (ACP). A análise considerou os efeitos de genótipos e ambientes como fixos e o modelo de acordo com a equação:

$\mathrm{Y}_{\mathrm{ij}}=\mu+\mathrm{g}_{\mathrm{i}}+\mathrm{a}_{\mathrm{j}}+\sum_{\mathrm{k}=1}^{\mathrm{n}} \lambda_{\mathrm{k}} \gamma_{\mathrm{ik}} \alpha_{\mathrm{jk}}+\rho_{\mathrm{ij}}+\varepsilon_{\mathrm{ij}}$

em que: $Y_{i j}$ é a média do genótipo i no ambiente j; $\mu$ é a média geral; $g_{i}$ e $a_{j}$ são os efeitos do i-ésimo genótipo e j-ésimo ambiente, respectivamente; $\lambda_{\mathrm{k}}$ é o k-ésimo valor singular da matriz GA (escalar); $\gamma_{\mathrm{ik}}$ e $\alpha_{\mathrm{jk}}$ são os elementos correspondentes ao i-ésimo genótipo e j-ésimo ambiente, nos vetores $\gamma_{\mathrm{k}}$ (vetor singular coluna) e $\alpha_{\mathrm{k}}$ (vetor singular linha), respectivamente; $\mathrm{n}$ é o número de componentes principais da interação GA retidos no modelo; $\rho_{\mathrm{ij}}$ é o resíduo da interação $\mathrm{GA}$; e $\varepsilon_{\mathrm{ij}}$ é o erro experimental médio.

O método AMMI pode gerar uma família de modelos (AMMI0, AMMI1, AMMI2, ...AMMIn). AMMI0 usa somente as médias de genótipos e ambientes para descrever o modelo e ordena os genótipos de forma idêntica em cada ambiente, descartando toda a interação GA. O segundo modelo, AMMI1, considera os efeitos principais (genótipos e ambientes), bem como o primeiro eixo da ACP da interação para interpretar a matriz residual. O modelo AMMI 2 considera os efeitos principais aditivos (genótipos e ambientes) e os dois primeiros eixos da ACP. Os eixos da ACP que apresentam seus resíduos nãosignificativos pelo teste $F_{R}$ de Cornelius (1993) podem ser ignorados, o que gera um modelo reduzido (Fox et al., 1997).

A análise estatística foi realizada utilizando-se o SAS (SAS Institute, 1997). O método produz escores de componentes principais de interação (IPCA) para cada genótipo, que refletem a sua contribuição para a interação
GA. Assim, o genótipo com o(s) menor(es) escore(s), em valor absoluto, é o mais estável (Silva \& Duarte, 2006).

A interpretação da adaptabilidade e da estabilidade foi realizada por meio da análise gráfica em biplot (Gabriel, 1971). No biplot AMMI1, a estabilidade é interpretada no eixo das abscissas, sendo considerados estáveis os genótipos e ambientes com valores de escores próximos de zero, já a adaptabilidade é interpretada no eixo das ordenadas, onde são plotadas as médias de genótipos e ambientes. O biplot AMMI2 permite interpretar a estabilidade de genótipos e ambientes, bem como interações específicas de genótipos com ambientes. Nele, a zona de estabilidade corresponde ao ponto de inteseção dos escores zero do primeiro e segundo componentes principais da interação (região central do biplot). Genótipos e ambientes próximos em qualquer área do gráfico representam adaptação específica do genótipo com o ambiente. As médias preditas pelo modelo AMMI selecionado foram acessadas para auxiliar na interpretação da adaptabilidade de genótipos e ambientes.

$\mathrm{Na}$ interpretação dos resultados de adaptabilidade e estabilidade, neste trabalho, a expressão alta adaptabilidade será utilizada como sinônimo de alta produtividade e, ampla adaptabilidade, como sinônimo de alta estabilidade/ previsibilidade, conforme Freire Filho et al. (2005b).

\section{Resultados e Discussão}

A análise de variância mostrou que os efeitos de genótipos, de ambientes e da interação genótipos $\mathrm{x}$ ambienets foram significativos (Tabela 1). Freire Filho et al. (2002, 2005b), ao investigar a adaptabilidade e a estabilidade de genótipos de feijão-caupi de porte prostrado também encontraram diferenças para ambientes e interação genótipo x ambiente, no entanto, não detectaram diferenças para genótipos.

Os efeitos de ambientes foram responsáveis pela maior parte da variação, seguido dos efeitos de genótipos e da interação genótipo x ambiente. Esses resultados concordam com os obtidos por Akande (2007), que estudou a interação genótipo $\mathrm{x}$ ambiente para a produtividade de grãos de oito cultivares de feijão-caupi no sudoeste africano, e encontraram maior variação para ambientes $(61,32 \%)$, entretanto, com magnitude menor do que a obtida neste estudo $(91,87 \%)$. 
Pelo critério do teste $\mathrm{F}_{\mathrm{R}}$ (Cornelius, 1993), o modelo selecionado foi o AMMI3, cujo resíduo não foi significativo. Resultado semelhante, quanto à seleção do modelo AMMI, foi obtida por Freire Filho et al. (2005b), no entanto, diferente do verificado por Akande (2007), que selecionou o modelo AMMI1.

Os três eixos explicaram $66,24 \%$ da soma de quadrados da interação genótipo $\mathrm{x}$ ambiente $\left(\mathrm{SQ}_{\mathrm{GA}}\right)$, sendo que o IPCA1 explicou 33,37\%, o IPCA2, $21,74 \%$, e o IPCA3, $11,13 \%$. Como $66,24 \%$ da $\mathrm{SQ}_{\mathrm{GA}}$ corresponde ao padrão adjacente à interação genótipo $\mathrm{x}$ ambiente e de importância agronômica, 33,76\% da $\mathrm{SQ}_{\mathrm{GA}}$ representa ruído, ou seja, variação aleatória resultante da influência de fatores microambientais e sem importância agronômica. As porcentagens explicadas pelos dois primeiros eixos da análise de componentes principais $(33,37$ e $21,74 \%)$ foram inferiores às obtidas por Freire Filho et al. (2003), mas superiores às obtidas por Freire Filho et al. (2005b). Segundo Freire Filho et al. (2003), a utilização de eixos remanescentes, que contêm mais ruído do que padrão, pode atrapalhar a interpretação da adaptabilidade e estabilidade via biplot. Os dois primeiros eixos explicaram 83,20\% do padrão da interação genótipo x ambiente e, por isso, a interpretação da adaptabilidade e estabilidade será realizada considerando-se apenas os dois primeiros eixos da análise de componentes principais (IPCA1 e IPCA2) por meio dos biplots AMMI1 (Figura 1) e biplot AMMI2 (Figura 2).

Quanto aos efeitos aditivos de genótipos e ambientes, observados pela dispersão na horizontal do biplot AMMI1, apesar de os genótipos variarem, essa variação foi menor, relativamente aos efeitos de ambientes e interação genótipo x ambiente, sendo esta observada na vertical do biplot AMMI1 e em toda a dispersão contida no biplot AMMI2 (Figura 2).

A variação observada nos ambientes se deve, provavelmente, à forte interação entre anos e locais ocasionada, principalmente, pela ocorrência de estresses abióticos, com predominância de irregularidades pluviométricas e presença de veranicos, comuns na Região Nordeste. Comportamento semelhante foi verificado por Freire Filho et al. (2005b), ao avaliar genótipos de feijão-caupi de porte prostrado nos mesmos ambientes. Segundo Annicchiarico (1997), ambientes localizados em regiões tropicais são mais propensos à ocorrência de estresses abióticos.

Três linhagens, EVX-63-10E, EVX-92-49E e TE97-321G-4, superaram a melhor testemunha, a cultivar BRS Guariba (1.403,19 $\mathrm{kg} \mathrm{ha}^{-1}$ ) (Figura 1 e Tabela 2). Os genótipos mais estáveis foram TE97-413-1F-2, EVX-63-10E, TE97-411-1F e EVX-47-6E, pois apresentaram os escores mais baixos para a interação GA e posições mais próximas do centro do biplot AMMI2. Os genótipos mais instáveis foram TE97-369G-4, TE97367G-12-2 e BRS Guariba, ambos mais distantes do centro do biplot AMMI2 (Figura 2).

A linhagem EVX-63-10E foi a mais produtiva e ao mesmo tempo a segunda mais previsível, evidenciando que esta reúne adaptabilidade geral (Eberhart \& Russel, 1966), podendo ser cultivada em todos os ambientes estudados. Também observa-se que a cultivar BRS Guariba, embora aparente ser estável pela interpretação do biplot AMMI1 (Figura 1), é altamente instável pela interpretação do biplot AMMI2 (Figura 2).

Tabela 1. Análise de efeitos aditivos principais e interação multiplicativa para o caráter produtividade de grãos $(\mathrm{kg}$ ha-1 $)$ de 20 genótipos de feijão-caupi de porte semi-ereto, avaliados em 16 ambientes da Região Nordeste do Brasil.

\begin{tabular}{|c|c|c|c|c|}
\hline Fonte de variação & GL & $\% \mathrm{SQ}_{\mathrm{T}}^{(1)}$ ou $\mathrm{SQ}_{\mathrm{GA} / \mathrm{PCA}}{ }^{(2)}$ & $\% \mathrm{SQ}_{\mathrm{GA}}$ Acumulada & $\mathrm{QM}$ \\
\hline Genótipos (G) & 19 & $6,95^{(1)}$ & - & $3.486 .322,36^{* *}$ \\
\hline Ambientes (A) & 15 & $91,87^{(1)}$ & - & $58.404 .985,63^{* *}$ \\
\hline GxA & 285 & $1,18^{(1)}$ & - & $39.502,55^{* *}$ \\
\hline IPCA1 & 33 & $33,37^{(2)}$ & 33,37 & $113.832,14^{* *}$ \\
\hline Resíduo $_{\text {АMMII }}$ & 252 & - & 66,63 & $29.768,91^{* *}$ \\
\hline IPCA2 & 31 & $21,74^{(2)}$ & 55,11 & $78.982,16^{* *}$ \\
\hline Resíduo $_{\text {АMMI2 }}$ & 221 & - & 44,89 & $22.865,69^{* *}$ \\
\hline IPCA3 & 29 & $11,13^{(2)}$ & 66,24 & $43.178,83^{* *}$ \\
\hline Resíduo $_{\text {AMMI3 }}$ & 192 & - & 33,76 & $19.797,56^{\mathrm{ns}}$ \\
\hline Erro médio/r ${ }^{(3)}$ & 912 & & & $6.353,84$ \\
\hline $\mathrm{CV}(\%)$ & 15,21 & & & \\
\hline
\end{tabular}

${ }^{(1)}$ Porcentagem da soma de quadrados de tratamentos. ${ }^{(2)}$ Porcentagem da soma de quadrados da interação genótipos x ambientes captada por IPCA

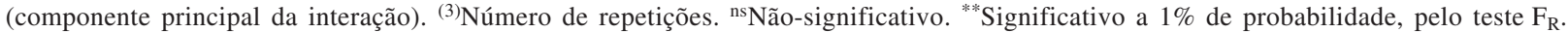


Esta última parece ser mais correta, tendo em vista que o biplot AMMI 2 contém informações dos IPCA1 e IPCA2, portanto contém mais padrão, relativamente ao biplot AMMI1, que considera apenas o IPCA1. A cultivar BRS Guariba representa um caso típico de adaptação específica a ambientes favoráveis, pois apesar de sua instabilidade, está entre os quatro genótipos mais produtivos (Tabela 2). A cultivar Vita-7 mostrou previsibilidade semelhante e adaptabilidade inferior às alcançadas por Freire Filho et al. (2001). Isso se deve, provavelmente, a diferenças em relação ao grupo de genótipos e ambientes utilizados nos dois estudos.

Quanto aos ambientes, os mais estáveis foram SD03, ST03, RC02 e NS03 (Figura 2), sendo os três primeiros associados à baixa produtividade e o último, associado à alta produtividade (Figura 1). Segundo Oliveira et al. (2003), a estabilidade ambiental tem grande importância, pois informa sobre a confiabilidade no ordenamento dos genótipos em um dado ambiente de teste, em relação à classificação para a média dos ambientes testados. Os ambientes mais instáveis foram SR02, BG02 e BJ03,

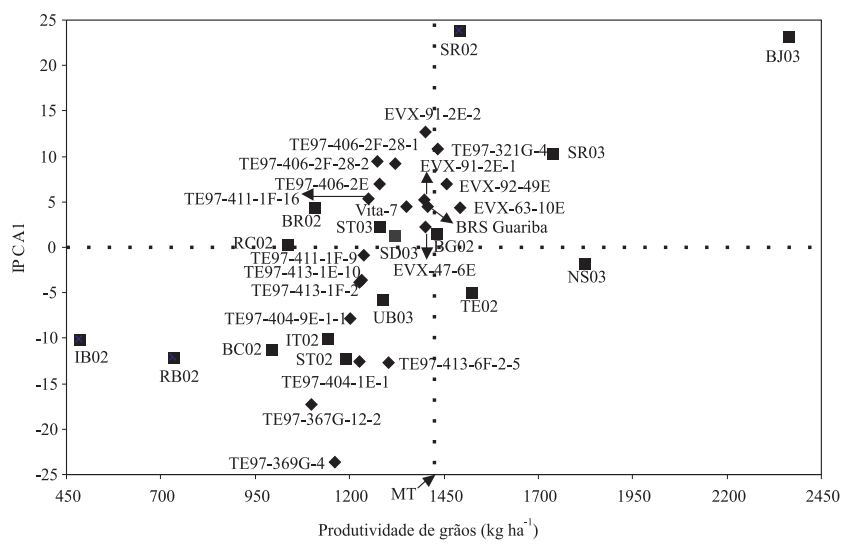

Figura 1. Biplot AMMI1: primeiro componente principal (IPCA1) x produtividade de grãos $\left(\mathrm{kg} \mathrm{ha}^{-1}\right)$, de 20 genótipos ( $\left.\boldsymbol{\square}\right)$ de feijão-caupi, avaliados em 16 ambientes $(\downarrow)$ da Região Nordeste do Brasil (Brejo, MA, 2002: BR02; Barra do Corda, MA, 2002: BC02; São Raimundo das Mangabeiras, MA, 2002: SR02; São Raimundo das Mangabeiras, MA, 2003: SR03; Teresina, PI, 2002: TE02; Baixa Grande do Ribeiro, PI, 2002: BG02; Bom Jesus, PI, 2003: BJ03; Serra Talhada, PE, 2002: ST02; Serra Talhada, PE, 2003: ST03; Nossa Senhora das Dores, SE, 2003: NS03; Simão Dias, SE, 2003: SD03; Umbaúba, SE, 2003: UB03; Ribeira do Pombal, BA, 2002: RB02; Itaberaba, BA, 2002: IB02; Riacho dos Cavalos, PB, 2002: RC02 e Itaporanga, PB, 2002: IT: 02). MT: média da testemunha. e este último, ao apresentar instabilidade associada com alta produtividade, evidencia que o local Bom Jesus apresentou interação positiva com o ano agrícola de 2003. Esse resultado discorda dos obtido por Freire Filho et al. (2003, 2005b), que estudaram genótipos de feijão-caupi de porte prostrado e encontraram comportamento previsível para o local Bom Jesus, PI. A instabilidade do local Teresina, PI, relatada por esses autores, não foi observada neste trabalho. Houve tendência de agrupamento quanto à interação GA para ambientes pertencentes aos estados do Sergipe (Nossa Senhora das Dores, 2003; Simão Dias 2003 e Umbaúba, 2003) e da Bahia (Ribeira do Pombal, 2002 e Itaberaba, 2002). Nos demais, a interação GA foi dissimilar para ambientes dentro de cada Estado, conforme pode ser observado no biplot AMMI2 (Figura 2).

A interpretação gráfica em biplot na análise AMMI permitiu identificar com eficácia genótipos superiores, ou seja, previsíveis e com média acima das testemunhas, corroborando resultados obtidos por Rocha et al. (2004) e Freire Filho et al. (2005).

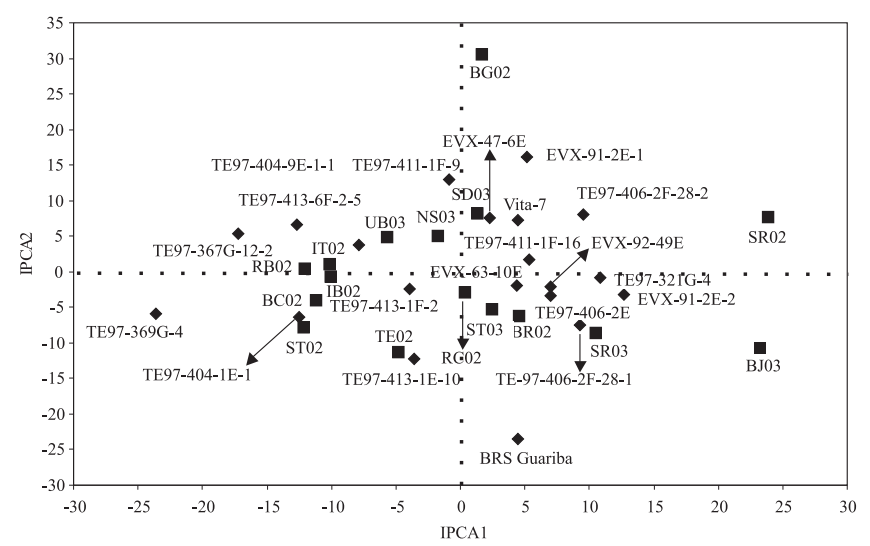

Figura 2. Biplot AMMI2 - Primeiro componente principal (IPCA1) x segundo componente principal da interação (IPCA2), de 20 genótipos ( $\boldsymbol{\square}$ ) de feijão-caupi, avaliados em 16 ambientes $(\diamond)$ da Região Nordeste do Brasil (Brejo, MA, 2002: BR02; Barra do Corda, MA, 2002: BC02; São Raimundo das Mangabeiras, MA, 2002: SR02; São Raimundo das Mangabeiras, MA, 2003: SR03; Teresina, PI, 2002: TE02; Baixa Grande do Ribeiro, PI, 2002: BG02; Bom Jesus, PI, 2003: BJ03; Serra Talhada, PE, 2002: ST02; Serra Talhada, PE, 2003: ST03; Nossa Senhora das dores, SE, 2003: NS03; Simão Dias, SE, 2003: SD03; Umbaúba, SE, 2003: UB03; Ribeira do Pombal, BA, 2002: RB02; Itaberaba, BA, 2002: IB02; Riacho dos Cavalos, PB, 2002: RC02 e Itaporanga, PB, 2002: IT02). 
Tabela 2. Médias preditas do caráter produtividade de grãos $\left(\mathrm{kg} \mathrm{ha}^{-1}\right)$ pelo modelo de efeitos aditivos principais e interação multiplicativa, considerando apenas os três primeiros eixos da análise de componentes principais da interação (AMMI3) de 20 genótipos de feijão-caupi avaliados em 16 ambientes da Região Nordeste do Brasil.

\begin{tabular}{|c|c|c|c|c|c|c|c|c|c|c|c|c|c|c|c|c|c|}
\hline \multirow[t]{2}{*}{ Genótipos } & \multicolumn{17}{|c|}{ Ambientes ${ }^{(1)}$} \\
\hline & BR02 & $\mathrm{BC} 02$ & SR02 & SR03 & TE02 & BG02 & BJ03 & ST02 & ST03 & NS03 & SD03 & UB03 & RB02 & IB02 & $\mathrm{RC} 02$ & IT02 & Média \\
\hline TE-97-321G-4 & 1.319 & 1.048 & 1.867 & 2.018 & 1.555 & 1.542 & 2.738 & 1.190 & 1.436 & 1.930 & 1.442 & 1.339 & 752 & 500 & 1.155 & 1.162 & 1.434 \\
\hline TE-97-404-1E-1 & 1.073 & 1.085 & 1.061 & 1.648 & 1.467 & 1.126 & 2.030 & 1.312 & 1.202 & 1.743 & 1.148 & 1.230 & 849 & 529 & 943 & 1.195 & 1.228 \\
\hline TE-97-404-9E-1-1 & 1.089 & 974 & 1.209 & 1.673 & 1.169 & 1.401 & 1.969 & 1.152 & 1.138 & 1.773 & 1.179 & 1.206 & 831 & 444 & 854 & 1.152 & 1.201 \\
\hline TE-97-406-2-E & 1.098 & 896 & 1.608 & 1.776 & 1.548 & 1.316 & 2.547 & 1.099 & 1.282 & 1.759 & 1.286 & 1.210 & 597 & 389 & 1.032 & 1.029 & 1.279 \\
\hline TE-97-406-2F-28-1 & 1.229 & 935 & 1.670 & 1.934 & 1.542 & 1.226 & 2.663 & 1.149 & 1.354 & 1.786 & 1.278 & 1.206 & 649 & 409 & 1.066 & 1.056 & 1.322 \\
\hline Тe-97-406-2F-28-2 & 981 & 812 & 1.746 & 1.643 & 1.483 & 1.670 & 2.499 & 972 & 1.221 & 1.797 & 1.394 & 1.257 & 529 & 355 & 1.014 & 999 & 1.273 \\
\hline TE-97-411-1F-9 & 930 & 867 & 1.476 & 1.523 & 1.306 & 1.740 & 2.123 & 1.012 & 1.123 & 1.802 & 1.342 & 1.271 & 661 & 401 & 915 & 1.078 & 1.223 \\
\hline TE-97-411-1F-16 & 1.077 & 870 & 1.570 & 1.736 & 1.393 & 1.430 & 2.404 & 1.052 & 1.224 & 1.766 & 1.277 & 1.202 & 624 & 371 & 968 & 1.033 & 1.250 \\
\hline TE-97-413-1E-10 & 1.218 & 1.018 & 1.229 & 1.865 & 1.388 & 953 & 2.275 & 1.255 & 1.260 & 1.712 & 1.091 & 1.138 & 790 & 442 & 940 & 1.116 & 1.231 \\
\hline TE-97-413-1F-2 & 1.081 & 971 & 1.292 & 1.698 & 1.389 & 1.257 & 2.190 & 1.175 & 1.201 & 1.745 & 1.191 & 1.200 & 741 & 439 & 935 & 1.109 & 1.226 \\
\hline TE-97-413-6F-2-5 & 1.004 & 1.105 & 1.228 & 1.542 & 1.498 & 1.606 & 1.990 & 1.285 & 1.207 & 1.872 & 1.351 & 1.385 & 886 & 603 & 1.005 & 1.272 & 1.302 \\
\hline TE-97-367G-12-2 & 821 & 962 & 906 & 1.338 & 1.278 & 1.353 & 1.681 & 1.149 & 1.001 & 1.677 & 1.120 & 1.194 & 761 & 444 & 791 & 1.122 & 1.100 \\
\hline TE-97-369G-4 & 665 & 1.117 & 755 & 1.154 & 1.919 & 1.095 & 1.827 & 1.371 & 1.098 & 1.648 & 1.175 & 1.302 & 709 & 595 & 990 & 1.176 & 1.162 \\
\hline EVX-47-6E & 1.171 & 1.032 & 1.689 & 1.797 & 1.503 & 1.757 & 2.423 & 1.194 & 1.337 & 1.951 & 1.474 & 1.401 & 810 & 550 & 1.103 & 1.221 & 1.447 \\
\hline EVX-63-10E & 1.525 & 1.157 & 1.749 & 2.199 & 1.384 & 1.532 & 2.584 & 1.343 & 1.492 & 2.025 & 1.423 & 1.388 & 1.012 & 614 & 1.147 & 1.326 & 1.494 \\
\hline EVX-91-2E-1 & 1.007 & 950 & 1.826 & 1.622 & 1.587 & 2.034 & 2.451 & 1.085 & 1.292 & 1.963 & 1.587 & 1.452 & 686 & 519 & 1.125 & 1.169 & 1.397 \\
\hline EVX-91-2E-2 & 1.253 & 953 & 1.864 & 1.966 & 1.626 & 1.446 & 2.795 & 1.151 & 1.417 & 1.872 & 1.411 & 1.296 & 656 & 452 & 1.151 & 1.094 & 1.400 \\
\hline EVX-92-49E & 1.104 & 1.054 & 1.808 & 1.768 & 1.979 & 1.555 & 2.784 & 1.264 & 1.449 & 1.915 & 1.534 & 1.435 & 657 & 578 & 1.273 & 1.171 & 1.458 \\
\hline Vita-7 & 1.162 & 960 & 1.686 & 1.804 & 1.399 & 1.693 & 2.416 & 1.120 & 1.294 & 1.899 & 1.413 & 1.329 & 753 & 475 & 1.042 & 1.154 & 1.350 \\
\hline BRS-Guariba & 1.278 & 1.127 & 1.537 & 1.986 & 2.016 & 831 & 2.858 & 1.417 & 1.508 & 1.780 & 1.268 & 1.269 & 703 & 560 & 1.244 & 1.146 & 1.408 \\
\hline Média & 1.104 & 992 & 1.489 & 1.734 & 1.521 & 1.428 & 2.362 & 1.187 & 1.277 & 1.821 & 1.319 & 1.286 & 733 & 483 & 1.035 & 1.139 & \\
\hline
\end{tabular}

(1)Brejo, MA, 2002: BR02; Biplot AMMI2 - Primeiro componente principal (IPCA1) x segundo componente principal da interação (IPCA2), de 20 genótipos de feijão-caupi, avaliados em 16 ambientes da Região Nordeste do Brasil (Brejo, MA, 2002: BR02; Barra do Corda, MA, 2002: BC02; São Raimundo das Mangabeiras, MA, 2002: SR02; São Raimundo das Mangabeiras, MA, 2003: SR03; Teresina, PI, 2002: TE02; Baixa Grande do Ribeiro, PI, 2002: BG02; Bom Jesus, PI, 2003: BJ03; Serra Talhada, PE, 2002: ST02; Serra Talhada, PE, 2003: ST03; Nossa Senhora das dores, SE, 2003: NS03; Simão Dias, SE, 2003: SD03; Umbaúba, SE, 2003: UB03; Ribeira do Pombal, BA, 2002: RB02; Itaberaba, BA, 2002: IB02; Riacho dos Cavalos, PB, 2002: RC02 e Itaporanga, PB, 2002: IT02). 


\section{Conclusões}

1. Os genótipos EVX-63-10E, EVX-92-49E e TE97321G-4 aproveitam vantajosamente os efeitos dos ambientais estudados, ao passo que TE97-413-1F-2 e TE97-411-1F-16 são altamente previsíveis frente aos ambientes estudados.

2. O genótipo EVX-63-10E reúne adaptabilidade e estabilidade, e pode ser indicado para todos os ambientes estudados.

3. A cultivar BRS Guariba e as linhagens EVX-9249E e TE97-321G-4 são instáveis, mas apresentam interação positiva com os ambientes e são indicadas para ambientes melhorados ou mais tecnificados.

\section{Referências}

AKANDE, S.R. Genotype by environment interaction for cowpea seed yield and disease reactions in the forest and derived savanna agro-ecologies of south-west Nigeria. American-Eurasian Journal of Agricultural \& Environmental Science, v.2, p.163-168, 2007. ANNICCHIARICO, P. Joint regression vs. AMMI analysis of genotype-environment interactions for cereals in Italy. Euphytica, v.94, p.53-62, 1997.

CARDOSO, M.J.; RIBEIRO, V.Q. Desempenho agronômico do feijão-caupi, cv. Rouxinol, em função de espaçamento entre linhas e densidade de plantas sob regime de sequeiro. Revista Ciência Agronômica, v.37, p.102-105, 2006.

CORNELIUS, P.L. Statistical tests and retention of terms in the additive main effects and multiplicative interaction model for cultivar trials. Crop Science, v.33, p.1186-1193, 1993.

DUARTE, J.B.; VENCOVSKY, R. Interação genótipos x ambientes: uma introdução à análise 'AMMI'. Ribeirão Preto: Sociedade Brasileira de Genética, 1999. 60p. (Série Monografias, 9). EBERHART, S.A.; RUSSEL, W.A. Stability parameters for comparing varieties. Crop Science, v.6, p.36-40, 1966.

FOX, P.N.; CROSSA, J.; ROMAGOSA, I. Multi-environmental testing and genotype $\mathrm{x}$ environment interaction. In: KEMPTON, R.A.; FOX, P.N. (Ed.). Statistical methods for plant variety evaluation. London: Chapman \& Hall, 1997. p.117-138.

FREIRE FILHO, F.R.; LIMA, J.A.A.; RIBEIRO, V.Q. Feijãocaupi: avanços tecnológicos. Brasília, DF: Embrapa Informação Tecnológica, 2005a. 519p.

FREIRE FILHO, F.R.; RIBEIRO, V.Q.; ALCÂNTARA, J.P.; BELARMINO FILHO, J.; ROCHA, M.M. BRS Marataoã: nova cultivar de feijão-caupi com grão tipo sempre-verde. Revista Ceres, v.52, p.771-777, 2006.
FREIRE FILHO, F.R.; RIBEIRO, V.Q.; ROCHA, M.M.; LOPES, A.C.A. Adaptabilidade e estabilidade da produtividade de grãos de genótipos de caupi enramador de tegumento mulato. Pesquisa Agropecuária Brasileira, v.38, p.591-598, 2003.

FREIRE FILHO, F.R.; RIBEIRO, V.Q.; ROCHA, M.M.; LOPES, A.C.A. Adaptabilidade e estabilidade da produtividade de grãos de linhagens de caupi de porte ereto enramador. Revista Ceres, v.49, p.383-393, 2002.

FREIRE FILHO, F.R.; RIBEIRO, V.Q.; ROCHA, M.M.; LOPES, A.C.A. Adaptabilidade e estabilidade de rendimento de grãos de genótipos de caupi de porte semi-ereto. Revista Científica Rural, v.6, p.31-39, 2001.

FREIRE FILHO, F.R.; RIBEIRO, V.Q.; ROCHA, M.M.; LOPES, A.C.A. Adaptabilidade e estabilidade produtiva de genótipos de feijão-caupi. Ciência Rural, v.35, p.24-30, 2005 b.

GABRIEL, K.R. The biplot-graphical display of matrices with applications to principal component analysis. Biometrika, v.58, p.453-467, 1971.

MIRANDA, P.; COSTA, A.F.; OLIVEIRA, L.R.; TAVARES, J.A.; PIMENTEL, M.L.; LINS, G.M.L. Comportamento de Vigna unguiculata (L.) Walp., nos sistemas solteiro e consorciado III: tipo ramador. Pesquisa Agropecuária Pernambucana, v.10, p.67-76, 1997. Número especial.

OLIVEIRA, A.B.; DUARTE, J.B.; PINHEIRO, J.B. Emprego da análise AMMI na avaliação da estabilidade produtiva em soja. Pesquisa Agropecuária Brasileira, v.38, p.357-364, 2003.

ROCHA, M.M.; VELLO, N.A.; LOPES, A.C.A.; MAIA, M.C.C. Yield stability of soybean lines using additive main effects and multiplicative interaction analysis - AMMI. Crop Breeding and Applied Biotechnology, v.4, p.391-398, 2004.

SANTOS, C.A.F.; ARAÚJO, F.P. de; MENEZES, E.A. Comportamento produtivo de caupi em regimes irrigado e de sequeiro em Petrolina e Juazeiro. Pesquisa Agropecuária Brasileira, v.35, p.2229-2234, 2000.

SAS INSTITUTE. SAS/STAT software: changes and enhancements through release 6.12. Cary: SAS Institute, 1997. 1116p.

SILVA, W.C.J.; DUARTE, J.B. Métodos estatísticos para estudo de adaptabilidade e estabilidade fenotípica em soja. Pesquisa Agropecuária Brasileira, v.41, p.23-30, 2006.

SINGH, B.B.; EHLERS, J.D.; SHARMA, B.; FREIRE FILHO, F.R. Recent progress in cowpea breeding. In: FATOKUN, C.A.; TARAWALI, S.A.; SINGH, B.B.; KORMAWA, P.M.; TAMO, M. (Ed.). Challenges and opportunities for enhancing sustainable cowpea production. Ibadan: IITA, 2002. p.287-300. ZOBEL, R.W.; WRIGHT, M.J.; GAUCH, H.G. Statistical analysis of a yield trial. Agronomy Journal, v.80, p.388-393, 1988. 